\title{
Nickel isotopes in the ocean
}

\author{
NOLWENN LEMAITRE ${ }^{1 *}$, COREY ARCHER ${ }^{1}$, RiCARDO \\ ZAMORA $^{1}$, DEREK VANCE ${ }^{1}$ \\ ${ }^{1}$ Department of Earth Sciences, Institute of Geochemistry \\ and Petrology, ETH-Zürich, Clausiusstrasse 25, 8092 \\ Zürich, Switzerland \\ *nolwenn.lemaitre@erdw.ethz.ch
}

Nickel $(\mathrm{Ni})$ is an essential micronutrient for marine primary producers, but it is the least studied bioactive metal so far. Though surface $\mathrm{Ni}$ concentrations are never as depleted as some other metals, a large fraction of this Ni pool may not be bio-available, so that the importance of Ni as biolimiting may have been under-estimated. Oceanic $\mathrm{Ni}$ isotope data are still scarce, but recent studies have shown significant fractionation associated with uptake in the upper-ocean. Surprisingly, this shift to heavier isotopes towards the surface only occurs north of the Polar Front zone (PFZ), where surface concentrations are lower. This may be related to ecological zonation: south of the PFZ, diatoms take up smaller amounts of $\mathrm{Ni}$ without isotope fractionation whereas substantial $\mathrm{Ni}$ uptake, probably by cyanobacteria, is associated with isotope fractionation in the north.

Here, we present new data for dissolved $\mathrm{Ni}$ concentrations and isotopes from the Southern Ocean (ACE cruise) and North Atlantic (GEOVIDE cruise). At all stations, $\mathrm{Ni}$ displays concentrations decreasing from the deep to the surface ocean. This depletion is associated with a shift towards heavier $\mathrm{Ni}$ isotopes from a homogeneous deep ocean ( $>500 \mathrm{~m} ; \delta^{60} \mathrm{Ni}=1.37 \pm 0.06 \%$ for both cruises, $\mathrm{n}=58$ ) towards the upper-ocean $\left(\delta^{60} \mathrm{Ni}>1.60\right)$, indicating fractionation by phytoplankton uptake. Results from ACE, traversing the PFZ and the regions of formation of the different Southern Ocean water masses, relate the global distribution of $\mathrm{Ni}$ to other metals, and confirm that the shift to heavier isotopes in upper waters occurs within the PFZ.

As proposed in recent studies, diazotrophs, such as cyanobacteria, could play a role in this isotopic shift within the surface ocean. The different biogeochemical provinces crossed during GEOVIDE cruise make the North Atlantic a promising area to study the impact of different phytoplankton species (diatoms, coccolithophorids or cyanobacteria) on $\mathrm{Ni}$ concentrations and isotopes. In addition to the study of such internal cycling processes, GEOVIDE provides insights into sources and sinks (sediments, hydrothermalism, margins).

By combining these two new datasets with those already published, we will expand our analysis to the global ocean in order to better interpret the macronutrients $/ \mathrm{Ni} / \mathrm{Ni}$ isotope systematics. 